\title{
Demanda efetiva no longo prazo e no processo de acumulação: o debate sraffiano a partir do projeto de Garegnani (1962) *
}

\author{
Vivian Garrido Moreira ** \\ Franklin Serrano ***
}

\begin{abstract}
Resumo
O artigo discute a evolução do projeto sraffiano, iniciado em 1962 por Garegnani, de desenvolver uma teoria da demanda efetiva de longo prazo. Tratamos tanto dos aspectos metodológicos quanto analíticos, começando com a questão da compatibilidade entre o princípio da demanda efetiva e a abordagem clássica do excedente. Discutimos as relações entre os graus efetivo e normal da utilização da capacidade e o problema do caráter dual do investimento. A seguir relacionamos estes conceitos com a noção de posições de longo prazo e a análise do processo de ajustamento da capacidade à demanda no processo de acumulação de capital.
\end{abstract}

Palavras-chave: Garegnani; Demanda efetiva; Acumulação; Abordagem do excedente; Investimento induzido.

\begin{abstract}
Effective demand in the long period and in the process of accumulation: the Sraffian debate based on Garegnani's project (1962)

We discuss the evolution of the Sraffian project, initiated in 1962 by Garegnani, developing a long period theory of effective demand, analyzing its methodological and analytical aspects. Starting with the question concerning the compatibility between the principle of effective demand and the classical surplus approach, we then deal with the relationship between the actual and normal degrees of capacity utilization and the problem of the dual character of investment. These concepts are then related to the notion of long period positions and the analysis of the adjustment of capacity to demand in the process of capital accumulation.
\end{abstract}

Keywords: Garegnani; Effective demand; Accumulation; Surplus approach; Induced investment. JEL B31, B51, O11, O40.

\section{Introdução: o relatório SVIMEZ de 1962}

O programa de pesquisa sraffiano, no seu conteúdo mais amplo, vem evoluindo através de alguns polos, ditos "separados", pois, a teorização de cada um destes pode ser feita de modo parcialmente independente dos outros (Garegnani, 2007). A obra de Sraffa (1960) é o ponto de partida e o centro de referência para uma

\footnotetext{
*Artigo recebido em 8 de setembro de 2016 e aprovado em 18 de julho de 2017.

${ }^{* *}$ Pós doutoranda do Departamento de Ciências Econômicas da Universidade Estadual de Londrina (UEL), Londrina, PR, Brasil. E-mail: vivian_garrido@yahoo.com.br.

*** Professor Associado do Instituto de Economia da Universidade Federal do Rio de Janeiro (IE-UFRJ), Rio de Janeiro, RJ, Brasil. E-mail: franklinserrano@ gmail.com.
} 
retomada das teorias que se baseiam no conceito de excedente. Sraffa reconstruiu a teoria da distribuição e dos preços relativos baseado na economia política clássica (e Marx) de onde se origina a atual abordagem do excedente e retomou de modo ampliado essa antiga abordagem. Essas teorias separadas, que estão fora do núcleo da teoria da distribuição e dos preços relativos, têm como objeto de estudo as variáveis tomadas como exógenas no livro de Sraffa, quais sejam: uma das variáveis distributivas (o salário real ou a taxa de lucro), dada por fatores políticoinstitucionais, sendo a outra variável determinada residualmente com base no excedente; as técnicas disponíveis e os níveis setoriais e agregado do produto, bem como sua taxa de crescimento.

O presente trabalho diz respeito a teoria da determinação do produto agregado e de sua evolução no tempo, o que o conecta com a teoria da acumulação, dentro da abordagem sraffiana. Vamos examinar criticamente a evolução do programa de pesquisa iniciado por Garegnani (1962), no qual, tanto o nível do produto agregado quanto o processo de acumulação são liderados pela demanda, sustentados a partir da teoria da demanda efetiva de Keynes e Kalecki, em um contexto de longo prazo. Neste caso, os preços de produção relativos e a distribuição funcional da renda são determinados de acordo com a abordagem do excedente. Para orientar esta pesquisa, tomaremos como referência fundamental o trabalho pioneiro de Garegnani (1962), cuja publicação nos meios científicos se fragmentou em várias etapas.

Este trabalho se constitui num relatório de pesquisa encomendado pela fundação Svimez ${ }^{1}$ para estudos sobre o desenvolvimento do sul da Itália, intitulado "O problema da demanda efetiva no desenvolvimento italiano". Tal relatório estava divido em duas partes: uma teórica e uma aplicada. Na parte teórica, Garegnani se debruça sobre as então recentes contribuições de Sraffa (1960) e Garegnani (1960) acerca dos fundamentos da abordagem do excedente e da crítica à abordagem marginalista, para argumentar que o crescimento da economia e do emprego a longo prazo, mesmo na região mais atrasada da Itália, era basicamente restrito pela demanda e não por fatores de oferta. Além do interesse especifico da pesquisa e sua proposta, o que tornou este relatório bastante influente entre sraffianos foi o grau de detalhamento e rigor da parte de fundamentos teóricos, assim como a originalidade da visão de crescimento liderado pela demanda efetiva a longo prazo e compatível com a abordagem clássica do excedente proposta por Garegnani.

Porém, embora inovadora, a publicação desta análise teórica dentro de um relatório de pesquisa em edição limitada e escrito em italiano certamente restringiu

(1) A SVIMEZ (Associazione per lo SVIluppo dell'industria nel MEZzogiorno, associação para o desenvolvimento da indústria na região do Mezzogiorno, sul da Italia) é uma associação sem fins lucrativos fundada em 1946 com o objetivo de realizar estudos econômicos visando promover a industrialização na região sul da Itália, região tradicionalmente menos desenvolvida em termos econômicos e sociais que o norte do país. 
o seu impacto inicial. Aos poucos e ao longo dos anos, capítulos isolados da parte teórica do relatório, em versões substancialmente revisadas, foram sendo publicados nos meios acadêmicos. Esta parte teórica também se dividia em duas partes ${ }^{2}$ : uma mais crítica, onde se examinava a relação entre as diferentes abordagens para a teoria da distribuição e preços relativos e as teorias do produto e emprego; e uma parte mais construtiva, onde se delineavam aspectos da visão de crescimento liderado pela demanda proposta. Esta parte construtiva, por sua vez, também se compunha de duas partes: uma onde se examinavam as consequências mais gerais da independência, mesmo a longo prazo, do investimento em relação à poupança de plena capacidade; e outra onde se discutiam os principais determinantes do investimento das empresas privadas nesta visão.

A parte crítica foi revisada e publicada em revista na Itália em 1964/1965 e em inglês apenas em 1978/1979 (Garegnani, 1978/1979). Este se tornou provavelmente o artigo mais influente de Garegnani. Já a parte construtiva foi publicada de forma mais fragmentada. Inicialmente circulou, e só parcialmente, em cópias mimeografadas a partir de um paper apresentado numa conferencia (Garegnani, 1982). A versão definitiva só foi publicada num livro em 1992 (Garegnani, 1992), mas ainda era parcial. Finalmente, o restante desta parte construtiva (não revista pelo autor) só foi traduzida para o inglês e publicada postumamente em 2015 (Garegnani, 2015). Dado nosso interesse no debate internacional da literatura sraffiana, estes trabalhos serão discutidos aqui na ordem em que foram publicados em inglês.

Serão tratados tanto aspectos metodológicos quanto analíticos, começando com a questão mais geral da compatibilidade entre o princípio da demanda efetiva e a abordagem clássica do excedente (Garegnani, 1962 [1978-1979]) (seção 2). Prosseguiremos com seção 3, dividida entre a discussão da independência do investimento em relação a poupança de plena capacidade, isto é, da negativa da lei de Say no trabalho de Garegnani (subseção 3.1), tratando também de algumas implicações teóricas deste tema. Segue-se daí a incorporação deliberada do princípio da demanda efetiva no longo prazo, com base em aspectos relacionados ao processo de ajustamento da capacidade à tendência da demanda (subseção 3.2). Essas duas últimas subseções são construídas com base em Garegnani (1962[1992]). A partir deste ponto, apresentaremos os problemas e discussões característicos de um debate interno na literatura sraffiana, que, afinal, surgiram como resultado da incorporação do princípio da demanda efetiva a esta literatura, passando, respectivamente, pela caracterização das posições de longo prazo, o dimensionamento do grau de utilização normal e finalizando com o ajustamento da capacidade à demanda entre vários autores (seção 4). Finalmente, elencaremos os elementos presentes em Garegnani

(2) Ver Cesarato e Mongiovi (2015) e Petri (2000). 
(1962[2015]), que trazem, essencialmente, a intuição para a resolução das próprias críticas e controvérsias apresentadas na seção 4, fechando o artigo (seção 5).

\section{Conexão do princípio da demanda efetiva com a abordagem clássica do excedente: Garegnani (1978/1979)}

A análise que aqui faremos do trabalho de Garegnani se sustentará em três eixos fundamentais que compõem esta e as duas subseções da próxima seção.

O objetivo principal do artigo seminal de Garegnani - Notes on consumption, investment and effective demand - era mostrar a compatibilidade do princípio da demanda efetiva com a abordagem clássica do excedente, a partir da constatação de um dispensável uso da lei de Say por D. Ricardo, que, em resumo, poderia ser removida sem qualquer prejuízo estrutural para toda a construção teórica erigida por esse último para determinar a taxa de lucro. Assim, os fundamentos da estrutura analítica clássica, como geração de um excedente, relação inversa entre taxa de lucro natural (normal) e salário real, processo de escolha das técnicas etc., poderiam dispensar a hipótese de lei de Say para validarem-se. A sequência do texto mostra que não apenas a lei de Say, mas também o pleno-emprego ${ }^{3}$ surgem enquanto necessidade teórica, apenas a partir das incursões da teoria neoclássica, cuja estrutura fundamental, ao basear-se no princípio da substituição ${ }^{4}$ gera mecanismos endógenos, tanto garantindo a existência de demanda agregada correspondente a qualquer nível de oferta (lei de Say), quanto fazendo com que esse nível corresponda ao de pleno-emprego, caso não haja nenhum elemento de perturbação do mecanismo de mercado. Com isso, sempre que uma teoria econômica for fundamentada nos princípios marginalistas, também imporá logicamente, mesmo que ressalvando imperfeições de curto prazo, o mecanismo de adaptação da demanda à oferta (lei de Say), via substituição, e a tendência ao pleno-emprego. O rompimento com esses dois conceitos junto com a tentativa de estabelecer papel ativo para demanda efetiva no longo prazo implicaria, portanto, no rompimento com os fundamentos teóricos marginalistas, mas não com os fundamentos clássicos originais. Portanto, o projeto de pesquisa proposto por Sraffa, e fundamentalmente divulgado a partir deste trabalho de Garegnani, se abriu em três frentes: 1) a crítica e derrubada da estrutura

(3) Lembremos que a lei de Say não implica em pleno emprego do trabalho. Implica somente que, para todo volume de oferta haverá sempre uma demanda correspondente. Apenas dentro dos mecanismos teóricos da abordagem neoclássica (muita substitutabilidade entre fatores de produção) é que ocorre a coincidência entre esses dois conceitos, pois nesta abordagem o produto potencial da economia corresponde ao pleno emprego de todos os fatores, inclusive o trabalho, enquanto na visão clássica a mão de obra não é escassa.

(4) Mecanismo primordial no estabelecimento da inclinação negativa de curva de demanda por um bem ou fator de produção. A substituição se baseia no preço relativo dos bens ou fatores em questão. Pode haver substituição no consumo (bens finais) ou na produção (fatores produtivos), sendo que este último tipo, pode ser de origem direta, quando a substituição é feita diretamente devido ao barateamento relativo de um fator, ou indireta, quando a substituição de fatores se origina de uma anterior substituição no consumo em favor do bem mais intensivo no fator que ficou relativamente mais barato. 
interna da abordagem neoclássica; 2) a retomada da abordagem clássica original (ou abordagem do excedente) como alternativa para continuidade da pesquisa econômica; e 3) a conexão do princípio da demanda efetiva com a abordagem clássica.

A primeira frente mencionada acima, inicia-se, portanto, com a crítica ao mecanismo neoclássico de substituição de fatores. Essa crítica possui uma diferença essencial em relação à grande maioria das críticas à teoria neoclássica. O problema com a maioria das críticas é que elas se dão na construção de obstáculos ou imperfeições que atuam como barreiras ao pleno-emprego. A natureza desses obstáculos é sempre exógena à lógica central dos mecanismos neoclássicos de equilíbrio. Mesmo a obra de Keynes (1936), sofreria deste problema, de acordo com

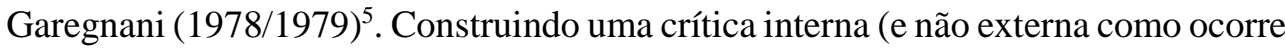
à maioria dos críticos da teoria neoclássica), Garegnani mostra que, independentemente de incerteza ou rigidez nominal de preços, salários ou da taxa de juros, ou qualquer outra imperfeição, o funcionamento dos mecanismos de condução ao pleno-emprego não pode ser assegurado numa economia, a menos que o capital seja homogêneo ${ }^{6}$, hipótese imprescindível para a lógica do argumento marginalista. Ao derrubar a lógica do mecanismo de substituição entre os fatores de produção, a crítica de Sraffa e Garegnani implica na quebra da relação inversa de longo prazo entre investimento e taxa de juros, bem como entre demanda por trabalho e salário real $^{7}$.

A partir desta crítica interna, a completa determinação do nível de atividade pela demanda não poderia ser reduzida ao caso em que a última aparece impedida por fatores exógenos, geralmente relacionados ao curto-prazo (na ausência dos quais chega-se necessariamente ao pleno-emprego), como postulado pela síntese neoclássica. Tratar-se-ia sim de um caso bem mais geral, onde, nem sob as hipóteses

(5) Garegnani (1978/79) argumenta que Keynes retém e não questiona a validade geral dos mecanismos marginalistas de substituição de fatores de produção, que estariam presentes tanto na função investimento elástica em relação aos juros quanto na relação inversa entre salário real e emprego. Sustenta também que isto força Keynes a usar elementos como a incerteza e a preferência pela liquidez para evitar que a economia retome a tendência ao pleno emprego e que a presença de tais elementos marginalistas abriu o caminho para a recuperação da ortodoxia pela síntese neoclássica de Modigliani, Hicks e Samuelson. Esta interpretação de Garegnani foi imediatamente questionada por Joan Robinson (1979) (ver réplica de Garegnani (1979a). Uma outra rodada deste debate foi publicada em italiano no livro de Garegnani (1979b) e só foi publicada em inglês em Garegnani (1989) (com as intervenções de Joan Robinson aparecendo nos apêndices). A avaliação deste debate, no entanto, vai além do objetivo do presente trabalho.

(6) O "capital" enquanto fator de produção homogêneo é um dos elementos centrais logicamente necessários à abordagem neoclássica para garantir o mecanismo de substituição que conduz ao pleno-emprego. Sempre que o capital for heterogêneo, ou seja, sempre que a relação capital/trabalho não for a mesma para todos os bens produzidos numa economia, os preços relativos vão mudar quando muda a distribuição e os mecanismos neoclássicos de equilíbrio não mais se sustentam. O caso geral, portanto, é aquele no qual o capital é heterogêneo. Ver Garegnani (2012).

(7) Ver Eatwell e Milgate (1983). 
mais favoráveis, a demanda possui qualquer mecanismo para se enquadrar à oferta. Dito de outra forma, através da crítica, depois conhecida por controvérsia do capital, chega-se à conclusão de que não é possível estabelecer uma resposta do investimento às decisões de poupança (sejam de pleno-emprego ou plena capacidade), não havendo qualquer mecanismo endógeno nesse sentido. Assim, a taxa de juros que para os neoclássicos exerceria o papel equilibrador entre as decisões de poupar e investir até que se chegue ao pleno-emprego, se torna irrelevante para este fim.

Uma vez que a lógica econômica não implique na ocorrência dos mecanismos neoclássicos de equilíbrio de mercado, a demanda deixa de limitar a produção apenas devido a fenômenos de curto-prazo (ou seja, perturbadores do equilíbrio), sendo estendida para uma análise do crescimento/longo prazo. Para atingir este objetivo, Garegnani apresenta uma proposta de continuidade da estrutura analítica da teoria clássica logicamente compatível com o princípio da demanda efetiva. A retomada da teoria clássica do valor já se origina em Sraffa (1960), e coube a Garegnani lançar as primeiras ideias de conexão da teoria sraffiana com o princípio da demanda efetiva.

Este programa de pesquisa tornará o nível de investimentos completamente independente da poupança de pleno-emprego e mesmo de plena capacidade (do capital já instalado), simplesmente porque não há qualquer necessidade teórica para que o investimento apresente essa convergência. A explicação para o volume do produto social agregado dependerá agora da demanda também no longo prazo, através de uma nova teoria para o volume de investimentos. Por outro lado, o volume de poupança será também dado pelo volume de investimentos. A não necessidade teórica do pleno-emprego leva, por sua vez, à retomada do conceito de desemprego estrutural dos clássicos, hipótese, inclusive, empiricamente mais plausível. Diferentemente da lógica neoclássica, não mais será necessária a rigidez do salário para "garantir" o desemprego estrutural; este existirá simplesmente porque a capacidade produtiva é que se ajustará à demanda no longo prazo e não o contrário (quando, na teoria neoclássica, era necessária a queda do salário para ajustar o produto potencial ao tamanho da força de trabalho e a flexibilidade da taxa de juros real garantiria que este produto de pleno emprego seria todo vendido). A ruptura com a abordagem marginalista rompe também com a lógica de determinação de salários e taxas de juros reais (e demais preços de fatores) de forma simultânea e endógena, retomando o paradigma clássico da distribuição de renda.

Enfim, ao romper com a abordagem neoclássica e recuperar o caminho para a retomada da abordagem clássica do excedente, Garegnani libera também o caminho para que a demanda agregada seja independente da oferta, num sentido amplo (determina a produção no presente e posteriormente induz investimento), e este é o primeiro passo para a ligação entre demanda efetiva e abordagem do 
excedente, sendo o primeiro eixo fundamental de Garegnani que gostaríamos de destacar neste trabalho.

\section{Independência do investimento em relação a poupança de plena capacidade e o ajuste da capacidade à tendência da demanda no processo de acumulação: Garegnani (1992)}

\subsection{A ausência de trade-off entre consumo e investimento em Garegnani (1992)}

O principal argumento deste artigo de Garegnani é mostrar que, no longo prazo, ou seja, aquele prazo no qual a capacidade produtiva pode mudar, a geração de poupança a partir da variação do investimento ocorre através da própria variação da capacidade produtiva e não de mudanças nas taxas de salários reais e de lucros. Isto permite que essas taxas continuem sendo determinadas, como na teoria clássica, por condições político-institucionais (Garegnani, 1992, p. 48).

Isso torna meramente temporária a natureza de grandes excessos ou deficiências de capacidade, não planejados em relação à demanda. O ajuste da poupança ao investimento se faria com o consumo variando na mesma direção do investimento, levando à variação da renda total e do produto potencial e não a uma alternativa entre os componentes de consumo e investimento, através do mecanismo de "poupança forçada" como na visão de Joan Robinson (1956, 1962), que só faria sentido se houvesse uma implausível restrição de oferta de longo prazo. Ao contrário, o processo seria de alargamento das margens para expansão do produto em resposta à demanda ao invés do estreitamento sugerido pelos teóricos de Cambridge (principal alvo crítico desse artigo), não havendo necessidade de mudanças no salário real e (consequentemente) na taxa de lucro para viabilizar o ajuste da poupança:

When it is capacity that adjusts to aggregate output, rather than output to capacity, the disappearance of excess capacity in the long period is the result of a low aggregate demand, and cannot therefore have acted as a constraint upon it, imposing a choice between consumption and investment and, hence, between wages and profits. And as soon as aggregate demand revives, the process of destruction of capacity will be set in reverse, and productive capacity will be recreated, leaving space for additional investment and consumption (Garegnani, 1992, p. 49-50, grifo nosso).

Outro ponto são as diferentes concepções possíveis para a taxa de lucro em conexão com o grau de utilização. Sobre isso, Garegnani destaca que o conceito clássico de taxa de lucro normal está associado à rentabilidade correspondente ao grau de utilização normal da capacidade, enquanto os autores de Cambridge utilizam também o conceito de taxa de lucro realizada, que mede a razão entre a massa de lucro realizada e o estoque de capital já instalado. Evidentemente, apenas no caso da 
taxa de lucro normal clássica existe necessariamente uma relação inversa entre o nível do salário real e a taxa de lucro. No caso da taxa de lucro realizada, a maior ou menor utilização efetiva do capital já instalado elimina a necessidade desta relação inversa. Na visão cambridgeana ocorre uma conexão direta entre acumulação e distribuição, de modo que a mudança na taxa de acumulação implica na mudança da taxa de lucro efetiva, que será a nova taxa de lucro "normal"; esta figurará no longo prazo com um grau de utilização que é mantido constante, pois a capacidade produtiva não se ajusta à demanda e sim a demanda agregada é que se ajusta à capacidade existente através de mudanças na distribuição (supondo que a propensão a consumir dos salários é mais alta do que dos lucros).

A proposta de Garegnani, que toma como variável de ajuste o próprio nível da capacidade produtiva (e não a distribuição ou o grau de utilização efetivo), implica que a concorrência (efetiva e potencial) imponha que a taxa de lucro contida na determinação dos preços normais seja a que é tomada como referência para os novos investimentos, ou seja, a taxa de lucro normal (obtida tendo como referência o grau de utilização normal). Isto ocorre porque os montantes de novos investimentos sempre serão efetuados com o objetivo de tentar criar capacidade para atender a demanda esperada ao grau de utilização normal, pois, ao mesmo tempo que não é nada lucrativo criar capacidade além do necessário, a concorrência impõe que as firmas não subdimensionem a capacidade em relação às suas concorrentes:

The profits expected from investing in a new plant will of course depend on the level of utilization expected for that plant. And that expected level of utilization will tend to be the 'desired' level because, by the very definition of the latter, the size of the new plant will be designed to make it such. The expected level of utilization will therefore tend to be independent of the levels of utilization and profits experienced in the past. A high past level of utilization of the plant might well result in a higher amount of investment, and a larger new plant, but there is no reason why it should imply a higher expected level of utilization of that plant (Garegnani, 1992, p. 56, grifos nossos).

Então, com base no princípio de ajuste do estoque de capital, o investimento induzido por um grau de utilização efetivo maior (menor) tenderá a ampliar (reduzir) o estoque de capital até que a massa de lucros realizados em relação ao último (a taxa de lucro realizada) se iguale à taxa de lucro normal, dada pelo salário real e pela tecnologia. Desse modo, é a taxa de lucro realizada que tende a se ajustar ao nível da taxa de lucro normal, dada agora exogenamente e não como uma variável de ajuste como na abordagem de Cambridge. Na abordagem sraffiana, apesar da relação inversa entre salário real e taxa de lucro normal e da tendência da taxa de lucro realizada se aproximar da taxa de lucro normal, não há conexão necessária entre 
acumulação e distribuição, mesmo com o grau de utilização tendendo a seu nível normal $^{8}$.

Portanto, concluímos esta subseção mostrando que o princípio do ajuste do estoque de capital garante um resultado efetivo de relação inversa entre as variáveis distributivas e de uma tendência à normalidade do grau de utilização que não se opera da mesma forma e não deve ser confundida com a versão de Cambridge, sendo, na verdade, o seu oposto, bem como o oposto da lei de Say. Isto decorre de uma versão consideravelmente mais "forte" do princípio da demanda efetiva, levada de fato para o longo prazo. Chegamos então ao segundo eixo fundamental de Garegnani para os fins deste trabalho: tanto a lei de Say quanto o ajuste de Cambridge, ou seja, as duas principais versões explicativas para um trade-off entre consumo e investimento, são inadequadas como instrumento analítico da abordagem sraffiana.

\subsection{A afirmação do princípio da demanda efetiva em Garegnani (1992)}

Garegnani (1992) segue evidenciando o papel do princípio da demanda efetiva a longo prazo, não através de uma análise detalhada do ajustamento da capacidade à demanda, mas especificamente mostrando "a influência no produto potencial futuro de qualquer falha na realização do produto potencial do período corrente, mostrando como, no longo prazo, aquele no qual a capacidade produtiva pode mudar, as margens para expansão do produto em resposta à demanda agregada podem se alargar ao invés de se estreitar" (Garegnani, 1992, p. 50, tradução nossa).

Para isso, o autor se baseia num esquema analítico muito simples, no qual a taxa de crescimento do investimento (e, portanto, do estoque de capital) é dado exogenamente e todo o consumo é induzido. Formalmente o esquema se reduz a algo como:

$$
\frac{I}{K}=\frac{I}{Y} \cdot \frac{Y}{Y^{*}} \cdot \frac{Y^{*}}{K}
$$

Onde $\mathrm{I} / \mathrm{K}$ é a taxa de crescimento do estoque de capital, I/Y é a parcela do investimento no produto, $\mathrm{Y} / \mathrm{Y}^{*}$ é o grau efetivo de utilização da capacidade e $\mathrm{Y} * / \mathrm{K}$

(8) Note que existem duas formas de pensar a tendência ao grau de utilização normal na abordagem clássica: a "Lei de Say" onde a demanda se ajusta à capacidade existente (Ricardo) e o princípio do ajuste do estoque de capital onde é a capacidade produtiva da economia que tende a se ajustar à tendência da demanda (Garegnani e seus seguidores). Note também que a versão de Joan Robinson/Cambridge não se enquadra exatamente em nenhuma das duas anteriores, apesar de manter a tendência ao grau de utilização normal. Neste caso, ela preserva a característica essencial da lei de Say de um trade-off entre consumo e investimento no longo prazo, o que remete, inevitavelmente, a algum tipo de restrição de oferta, mas o investimento não é determinado pela poupança potencial, e sim autônomo. Com a limitação na oferta, a expansão do investimento, só pode se "realizar" com redução do consumo, o que é gerado através da poupança forçada. 
é a relação técnica capacidade normal/capital (a inversa da relação normal capitalproduto, v). Dada a hipótese de consumo totalmente induzido e uma propensão média e marginal a consumir igual a (1-s), esta equação pode ser rescrita como:

$$
g=s / v \cdot u
$$

Garegnani (1992) usa uma equação deste tipo para mostrar que a taxa garantida s/v não é a taxa de crescimento, nem do produto, nem do produto potencial e sim a taxa máxima que o produto potencial poderia crescer se a utilização da capacidade fosse mantida em seu nível normal continuamente sem interrupções. Assim, demonstra que mesmo um desvio temporário da utilização normal (aqui $\mathrm{u}=1$ ), no qual ocorre uma subutilização por algum tempo e depois a taxa de crescimento do investimento volta ao valor da taxa garantida por hipótese, implicaria numa grande diferença cumulativa nos níveis futuros da capacidade produtiva da economia, por conta dos investimentos futuros que deixariam de ocorrer pois a capacidade produtiva que os acomodaria deixou de ser criada a partir da subutilização da capacidade corrente. Com base neste ponto, nota-se que o autor postula que uma redução do crescimento do investimento que cause uma determinada subutilização no presente implica na redução do ritmo de criação de capacidade produtiva, reduzindo seu tamanho potencial futuro, mesmo que se suponha, por hipótese que, no futuro, sejam restabelecidas as condições de crescimento equilibrado com $\mathrm{u}=1^{9}$.

A partir daí Garegnani tenta argumentar que é possível que a capacidade produtiva da economia e o produto cresçam em linha com a demanda a taxas muito variadas e independentes da taxa garantida. E que isso seria plenamente possível por meio de pequenos desvios no grau de utilização médio da capacidade em relação ao normal ao longo do tempo $(\mathrm{u} \neq 1)$ :

Through comparatively small increases (decreases) in the degree of utilization of existing capacity, changes in the level of investment can bring about those faster (slower) increases of productive capacity itself, which will then result in that rough correspondence between productive capacity and output which can be observed historically (Garegnani, 1992, p. 62, grifo nosso).

Percebamos como Garegnani, neste ponto, procura evidenciar que a demanda determina a oferta no seu sentido amplo (determina a produção corrente e induz o investimento), pois os desvios mencionados só aparecem na medida em que a demanda efetiva se diferencia da capacidade instalada e são eles que motivam, por sua vez (quando persistentes), a variação dos investimentos induzidos. Aqui fica intuído o princípio da demanda efetiva como instrumento analítico adequado para a abordagem do excedente no processo de acumulação e não apenas nos níveis de

(9) A perda cumulativa percentual de níveis futuros possíveis do produto potencial decorrente de uma subutilização da capacidade de $x \%$ por $t$ períodos seria dada pela formula: $x .((1+s / v)-1)$. 
produto (e não apenas a inadequação da lei de Say ou do mecanismo de poupança forçada). Este é o terceiro eixo fundamental de Garegnani que gostaríamos de apresentar. A forma como este opera, na prática, é evidenciada através da constatação de que a variabilidade do grau de utilização, a partir de uma capacidade produtiva inicial dada, é o fundamento para o alargamento ou estreitamento dos níveis futuros de capacidade produtiva.

To see that inconsistency let us consider an economy for which ... we are given (a) the real wage and the propensities to save out of wages and profits; and (b) the initial level of productive capacity. If then the average utilization of capacity over time were to be at the desired level, the path of future capital accumulation would be completely determined. Such a utilization of capacity would in fact be sufficient to determine the amount of investment of each period in the future in terms of the definite amount of savings forthcoming in that period under those conditions. ... That would allow for the determination of investment by the decisions to save, as in marginal theory, or for the determination of the real wage (normal rate of profits) by an independent amount of investment ... It would not, however, allow for any independent determination of investment which would leave the real wage (normal rate of profits) unaffected (Garegnani, 1992, p. 58).

Porém, a afirmação de que o desvio da utilização normal da capacidade ocorre em algum momento, obviamente não contradiz a tendência ao grau de utilização normal oriunda do ajuste do estoque de capital discutido na seção anterior (apesar da imprecisão que ainda envolvia a forma como isso se processa) ${ }^{10}$ e que, afinal, é o fundamento básico para explicar de que forma a demanda agregada esperada (e não a poupança potencial) determina o investimento. Garegnani deixa claro que não ignora que o investimento é induzido e que há uma "tendência dos empresários de ajustar a capacidade ao produto" (Garegnani, 1992, p. 59):

The entrepreneurs will certainly attempt to bring about, through investment, a capacity which can be used at the desired level. And the degree of their success will depend on how well they will be able to forecast the outputs which it will be convenient for them to produce. But given the initial arbitrary level of capacity that success will show only in shifting, so to speak, backward in time the deviation of the utilization of capacity from the desired level (Ibidem, p. 59 grifos nossos).

A presença dessa capacidade inicial arbitrária é que impediria que fosse logicamente possível se observar, salvo rara coincidência, um grau de utilização efetivo igual ao normal ao longo do tempo, seja no primeiro, seja em algum dos períodos seguintes. Ao mesmo tempo, é esse desvio da utilização normal, o

(10) Sobre o grau de utilização normal da capacidade, ver a seção 4.2 deste artigo. 
sinalizador para o ajustamento da capacidade à demanda, proposto pelo autor, numa economia onde a demanda efetiva determina a acumulação.

$\mathrm{O}$ artigo, porém, deixa aberta uma lacuna, pois, se de um lado o autor inicialmente supõe o investimento exógeno em seu exemplo, de outro está assumindo que o mesmo é, na realidade, totalmente induzido pela demanda esperada. A imprecisão sobre isso torna difícil entender em que condições seria logicamente possível o ajustamento da capacidade à demanda, sugerido por hipótese. Notemos que, embora o argumento de Garegnani esteja correto a respeito dos possíveis efeitos sobre os níveis de capacidade produtiva futura de pequenos desvios temporários do grau de utilização, basta examinar a equação da taxa garantida acima para notar que o mesmo não pode ser dito sobre a taxa de crescimento médio do investimento, da economia e da capacidade produtiva.

Por exemplo, uma redução permanente da taxa de crescimento exógena do investimento (e do capital) digamos de $3 \%$ para $1,5 \%$ ao ano implicaria numa enorme redução do grau médio efetivo de utilização da capacidade no esquema acima, que cairia para $50 \%$ da utilização normal permanentemente (se a queda fosse de $3 \%$ para $1 \%$, $u$ cairia para 0,33 ). Neste mesmo esquema, partindo de uma situação de utilização normal, uma aceleração do crescimento de $1,5 \%$ para $3 \%$ levaria a um grau de sobreutilização da capacidade permanente de $100 \%$, o que é ainda mais implausível. Essas variações enormes e permanentes são totalmente implausíveis e evidentemente incompatíveis com o que Garegnani queria demonstrar. Mas isso é claramente causado pela impossibilidade de supor uma taxa de crescimento do investimento exógena, que não reage às variações do grau de utilização, ao mesmo tempo em que é suposto um balanceamento entre capacidade e demanda no longo prazo. Por outro lado, se a taxa de crescimento do investimento for tornada endógena, ou seja, o investimento se tornar induzido, vai aparecer imediatamente o problema da instabilidade harrodiana, pois menores (maiores) valores de $u$ induziriam menores (maiores) valores de $g$, que levariam a menores (maiores) valores de $u$ e assim sucessivamente. Vemos aqui que, Garegnani (1992) mantém uma dificuldade analítica básica que se reproduzirá de formas variadas pela literatura.

Atente-se para a dualidade da ideia de que os pequenos desvios do grau de utilização, apesar de servirem de evidência de que o produto é determinado pela demanda, é justamente por serem pequenos - o que quer dizer que não se distanciam sistematicamente de sua gravitação para o nível normal - que eles evidenciam, simultaneamente, a existência de um movimento da capacidade produtiva total no sentido de se ajustar à demanda agregada. Caso contrário, isto é, se os desvios fossem se expandindo sistematicamente, estaríamos presenciando apenas que a demanda determina o nível efetivo de produto, mas não a capacidade. Embora seja bastante claro que a intenção do autor era provar ambos, é justamente neste último ponto que 
o problema do ajuste da capacidade fica tão malparado por tantos anos entre os sraffianos. A seguir, discutiremos parte dessas controvérsias.

\section{Rumo a esclarecimentos para o projeto de Garegnani: controvérsias sraffianas sobre a definição de longo prazo, de grau de utilização normal e sobre o ajuste da capacidade ${ }^{11}$}

Nas seções anteriores, o texto foi organizado com vistas a expor os argumentos de Garegnani a partir de três eixos fundamentais: 1) a crítica e descarte do caminho marginalista de teorização do crescimento econômico, reabrindo o caminho para a retomada da abordagem clássica do excedente; 2) a inadequação da lei de Say e também do ajuste de Cambridge dentro desta abordagem do excedente; 3) a adequação do princípio da demanda efetiva à estrutura analítica desta mesma abordagem. No final da última seção, vimos que, embora a intenção de Garegnani hoje nos pareça muito clara sobre o acolhimento teórico do princípio do ajuste do estoque de capital, o fato é que diversas controvérsias na literatura se levantaram sobre este ponto. Elencaremos aqui, três importantes discussões entre autores sraffianos: a concepção de longo prazo, a concepção de normalidade do grau de utilização e, a partir duas primeiras, a própria (e polêmica) concepção do princípio de ajustamento do estoque de capital no longo prazo.

\subsection{A caracterização da posição de longo prazo}

A caracterização da posição de longo prazo da economia já gerou bastante ambiguidade na literatura sraffiana. Todos os autores envolvidos concordam que nesta posição prevalecem os valores normais da taxa geral de lucros e dos preços relativos e pode existir amplo desemprego do trabalho. A problemática começa no questionamento sobre se o estoque de capital deve necessariamente estar plenamente ajustado (com o grau de utilização normal) ao nível (e composição) da demanda efetiva numa posição de longo prazo.

Segundo Eatwell (1979, 1983), Milgate (1982) e Eatwell e Milgate (1983), a resposta seria sim. Para Vianello (1985) também, a posição de longo prazo seria uma posição de "pleno ajustamento" da capacidade à demanda ${ }^{12}$. Ciccone (1986, 2011) e Garegnani (1992) argumentam que uma posição de longo prazo não necessita ser caracterizada desta forma e é compatível com situações onde o grau efetivo da utilização da capacidade produtiva (tanto agregado quanto setorial) pode ser bem diferente do seu nível normal ou planejado. Esta visão aparece inicialmente no trabalho de Ciccone (1986). Ali se reconhece que, num sistema de livre concorrência, o cálculo dos preços normais deve ser realizado tendo como referência o nível normal de utilização da capacidade (custo fixo por unidade de produto ao

(11) Mais detalhes sobre esta controvérsia encontram-se em Moreira (2007).

(12) Eatwell (2012) mantém sua posição a este respeito. Vianello (1989) muda de ideia a partir da aceitação da crítica de Ciccone (1986). 
nível da utilização normal da planta). Porém, isso não significa que o nível efetivo de utilização também precise ser normal para que sejam realizados os preços normais. Para a gravitação dos preços de mercado aos preços normais, é suficiente que a produção em cada setor (e não necessariamente a capacidade produtiva) se ajuste plenamente à demanda efetiva. Como a produção, em geral, possui bastante margem para se alterar através dos diferentes níveis de utilização da capacidade, não há necessidade de que a própria capacidade (ou seja, o estoque de capital total) esteja em sintonia fina com a demanda no conceito de longo prazo considerado pelo autor. Portanto, a princípio, é bastante provável, sobretudo devido a indivisibilidades e à longa vida útil de vários itens do estoque de capital fixo, que a produção e os preços se ajustem às suas posições de longo prazo com níveis de utilização ainda diferentes do normal.

Nesta situação, embora a taxa de lucro realizada sobre o capital já instalado possa diferir entre os setores, a taxa de lucro que se pode esperar nos novos investimentos é uniforme e igual à taxa de lucro normal ${ }^{13}$. Segundo Ciccone (1986) essa uniformidade da taxa de lucros nos novos investimentos requereria apenas, para um dado nível de demanda, que o tamanho relativo das indústrias seja tal que não torne mais lucrativo o investimento em qualquer delas em detrimento das outras. $\mathrm{E}$ isso, prescinde da hipótese de que o tamanho total do estoque de capital já existente deva manter alguma relação fixa com a demanda. Enfim, o que importa é que as quantidades produzidas estejam em consonância com a demanda efetiva, o que não implica que a capacidade produtiva também esteja e o grau de utilização seja normal. Entretanto, isso não nega que haja uma tendência de ajuste da capacidade à demanda. Mas afirma que as causas deste processo diferem daquelas concernentes ao ajuste de longo prazo dos preços, pois são causas relacionadas ao, bem mais prolongado e complexo, processo de acumulação de capital.

Ciccone (1986) deixa claro que o ajuste de preços de mercado aos preços normais e das quantidades produzidas e trazidas ao mercado à demanda efetiva são suficientes para caracterizar a tendência às posições normais de longo prazo da economia dentro da abordagem do excedente, e que isso nada implica sobre um possível estudo acerca do ajuste da capacidade:

What has just been said does not exclude the possibility that a tendency of capacity to assume a particular size relative to demand is constantly at work. There is no evident reason, however, for thinking that an adjustment of this type must take place 'simultaneously' with the gravitation of prices towards their long-period values; that tendency seems rather to give rise to a slower and more complex process, which implies net accumulation (positive or negative) for the economy as a whole ... in any case, a general accumulation or decumulation of capital cannot fail to have a wide-reaching effect on

(13) Determinada por uma variável distributiva exógena e os custos das técnicas dominantes operadas ao grau de utilização normal. 
aggregate demand itself, and the achievement of a particular size of capacity relative to that of demand appears in itself to be a process liable to be frustrated for long periods of time... these periods may be longer than those required for normal prices to show themselves as the central positions for actual prices - longer that is, than the "long period" itself. (Ciccone, 1986, p. 10).

É importante deixar claro que, apesar do grau de utilização normal não ser uma condição necessária para o ajuste à posição de longo prazo, ainda assim, é a referência utilizada para o cálculo dos preços normais que deverão prevalecer no longo prazo. Isso significa que, independente da capacidade instalada efetiva num dado momento, para cada novo processo de instalação de capacidade, a intenção de operá-la ao nível normal será sempre uma baliza para as decisões de investimento, na medida em que, para um dado nível de demanda, é, ao grau de utilização normal que será obtida a taxa de lucro normal (através dos preços normais).

Nesta concepção (utilizada também por Garegnani, 1992 e Ciccone, 2011) num contexto de longo prazo, tanto o produto quanto a capacidade variam e a demanda efetiva normal seria atendida tanto pela maior utilização da capacidade já instalada anteriormente quanto pela nova capacidade produtiva resultante de investimento mais recente. Este conceito de longo prazo mantém a ideia de que o longo prazo é longo o suficiente para que algum efeito-capacidade do investimento tenha que ser levado em conta, mas, ao mesmo tempo, não impõe que o prazo seja tão longo que o ajustamento da capacidade à tendência da demanda seja completo, pois assim que a produção se ajustar à demanda os preços de mercado não terão como se sustentar em níveis diferentes dos preços normais.

Uma implicação da distinção entre as velocidades de ajuste de preços e produção versus o ajuste da capacidade produtiva é que nesta concepção faz sentido falar em preços normais e produto setorial e agregado normais, mas, para evitar confusão terminológica e conceitual, não é recomendável o uso da expressão "capacidade produtiva normal" ou de longo prazo, já que a tendência a esta última se daria num prazo "mais longo que o longo prazo".

Apesar de Ciccone (1986, 2011) e Garegnani (1992) argumentarem em termos de que o ajuste da composição dos investimentos é suficiente para que a taxa de lucro esperada seja a taxa de lucro normal, o ponto central da questão da definição de uma posição de longo prazo com preços normais parece estar ligado ao processo de concorrência entre as empresas. Numa concepção clássica, quando os custos estiverem acima do normal, seja porque o grau de utilização está abaixo, seja porque está muito acima do grau normal de utilização ${ }^{14}$, a concorrência, de qualquer forma,

(14) Se o nível de utilização estiver abaixo do normal, o custo fixo por unidade de produto será maior que o normal. Se estiver um pouco acima do nível normal, os custos médios estariam caindo (o que leva a lucros extras, aos preços normais) até o ponto em que o grau de utilização se torna tão elevado que os custos médios começam a aumentar devido aos custos de se operar a capacidade muito acima do trecho minimizador de custos (ver seção 4.3 abaixo e Ciccone (1987). 
não permitiria que os preços fossem elevados acima do normal. A preços mais altos que os normais, outras firmas já no mercado podem estar operando mais próximas ao grau de utilização normal e poderiam aumentar suas parcelas de mercado às custas das firmas que aumentaram seus preços. Além disso, estes preços mais altos podem atrair novos entrantes no mercado que instalariam capacidade de tamanho mais adequado à demanda e obteriam lucros anormais às custas das firmas que aumentaram os preços. Assim, tanto a concorrência dos rivais no mercado quanto a dos concorrentes potenciais, garantem uma tendência de a demanda ser atendida aos preços normais e, conforme observa Garegnani (1979b), a taxa de lucro normal refere-se àquela que estaria sendo realizada no presente por produtores que estivessem utilizando a capacidade ao grau de utilização normal, mesmo quando o grau médio efetivo de utilização da capacidade em um mercado e na economia como um todo estiver bem diferente do normal. Toda esta discussão implica, por seu turno, numa outra controvérsia, envolvendo a própria definição de grau de utilização normal, que é o que vamos discutir a seguir.

\subsection{A definição do grau de utilização normal ou planejado}

Uma outra discussão importante diz respeito à própria caracterização dos determinantes do que seria o grau de utilização "normal" da capacidade produtiva em termos de capital fixo. Para Ciccone (1986), na linha aberta por Steindl (1952) a concorrência impõe que as empresas invistam em capacidade grande o suficiente para atender os picos esperados de demanda durante a vida útil dos equipamentos. Dessa forma, o padrão usual (ou convencional) da razão entre média e pico da demanda em cada setor determinaria o grau de capacidade ociosa planejada. Esta relação pico/média refletiria o padrão sazonal e de outras oscilações da demanda observados ao longo de muitos ciclos econômicos e, portanto, o grau de utilização normal de cada setor é tomado basicamente como um parâmetro exógeno na análise da determinação do produto e da acumulação de capital. Kurz (1986) critica esta visão, chamando a atenção para o fato de que o próprio modo de operação do capital fixo, por si só, constitui um típico problema de escolha de técnicas e que mudanças na distribuição de renda e nos preços relativos podem alterar de maneira complexa a técnica escolhida.

Dessa maneira, segundo Kurz (1986), frequentemente pode não valer a pena aumentar o grau de utilização para atender aumentos de demanda, porque, mediante a necessidade de mudança para um regime mais intenso de operação da planta, os custos de produção aumentariam ${ }^{15}$ e, mediante uma dada configuração da distribuição e preços relativos, não haveria vantagem em efetuar este aumento no

(15) A ideia de aumento de custos está relacionada à remuneração de horas extras ao trabalho, cujo valor tende a ser maior do que o das horas ordinárias, ou, analogamente, ao aumento da remuneração por hora da mão-deobra mais produtiva ou qualificada, ou ainda, ao aumento dos custos com depreciação do capital fixo por unidade de tempo. 
grau de utilização. Só valeria a pena alterar o regime de operação da planta se houver mudanças nos preços mais que compensando o aumento dos custos. Finalmente vale notar que, nessa análise, a economia só "escapa" do grau de utilização normal quando migra para "outro" grau de utilização normal, ou melhor, o próprio grau de utilização normal é redimensionado para cada mudança nos preços/distribuição e, desde que os empresários estejam minimizando os custos, a economia sempre estará operando sob o grau de utilização normal.

Ciccone (1987) responde ao artigo de Kurz (1986) reafirmando as ideias de Ciccone (1986). O trabalho se pauta na consideração central das flutuações de demanda para determinação do grau de utilização normal. Exatamente pelo fato de os empresários saberem que a demanda tende a flutuar significativamente, e serem obrigados a atender os picos de demanda, procuram, sistematicamente, calcular a dimensão da capacidade com alguma folga de ociosidade já planejada. A técnica minimizadora de custos não deixa de ser escolhida na tomada de decisão de investimento, mas, ao contrário de Kurz, a minimização se daria para uma capacidade produtiva máxima, suficiente para atender os picos, não a média, de demanda esperada. Com isso fica determinado o grau de capacidade ociosa já planejada no equipamento. Neste caso, ao contrário do que ocorre na análise de Kurz, o desvio do grau de utilização efetivo em relação ao normal não deve implicar em maiores custos, uma vez que o estoque de capital não será sobrecarregado e sim a quantidade de capital utilizada aumentará paralelamente ao aumento das horas trabalhadas. Como a planta é calculada com alguma margem ociosa, o aumento do grau de utilização acima do normal, deve gerar ganhos de escala, reduzindo os custos unitários até o limite da capacidade máxima, naquele regime de operação.

\subsection{Ajustamento da capacidade à demanda}

\subsubsection{Condições necessárias para o ajustamento}

Finalmente, chegamos à controvérsia central deste debate. Antes de entrar na literatura, é importante apontar que duas condições lógicas são estritamente necessárias (mas não suficientes) para que se postule uma tendência da capacidade produtiva se ajustar a demanda. A primeira, um tanto óbvia, é que, no contexto do processo de acumulação, o investimento privado que cria capacidade produtiva para o setor privado da economia seja endógeno e induzido pelo princípio de ajuste do estoque de capital (portanto, torna-se impraticável que o investimento agregado seja exógeno determinado por animal spirits ou outros elementos) e o seu total tenda ao valor requerido que gere o estoque de capital necessário para atender a demanda efetiva agregada e sua evolução no tempo. Chamaremos esta condição de condição 1. 
A segunda condição necessária é que seja possível que na economia em questão o investimento cresça mais ou menos que o consumo (ou em termos mais gerais do que os gastos que não criam capacidade para o setor privado). Somente no caso de que o investimento possa variar mais ou menos do que o consumo será possível que posteriormente o estoque de capital cresça mais ou menos rápido do que a demanda agregada, e o ajustamento da capacidade à demanda seja logicamente possível. No caso de uma empresa ou mesmo de um setor da economia, essa condição lógica é sempre facilmente atendida, pois o investimento de uma firma ou setor isolado terá efeitos muito limitados em termos de aumento induzido da demanda por produtos desta firma ou deste setor. Assim, no caso de subutilização da capacidade basta apenas que o investimento da firma ou do setor aumente menos do que a sua demanda para que haja uma tendência à utilização normal. Da mesma forma, no caso de uma utilização da capacidade acima do nível normal, basta que o investimento da empresa ou setor cresça mais do que sua demanda, para que o desequilíbrio tenda a ser corrigido. Logo, no nível de uma firma ou setor essa condição necessária para o ajustamento ir na direção certa é facilmente atendida (embora não impeça em si a possibilidade de overshooting e, logo, não é uma condição suficiente).

Em nível macroeconômico, no entanto, a questão não é tão simples. O investimento agregado tem, naturalmente, um forte efeito no consumo agregado através do mecanismo do multiplicador. E se não houver outros gastos (autônomos) que não criam capacidade, variações do investimento não vão mudar a taxa de investimento, isto é, o investimento e o consumo sempre vão aumentar na mesma proporção. Neste caso o ajustamento da capacidade à demanda é logicamente impossível, pois qualquer aumento ou queda do investimento levará a um aumento ou queda proporcional do consumo. Como o investimento primeiro gera demanda (tanto diretamente quanto via multiplicador), e só posteriormente altera a capacidade produtiva, tentativas de, por exemplo, corrigir um grau de utilização da capacidade inicial inferior ao normal, através da redução do crescimento do investimento, vão primeiro reduzir ainda mais o crescimento da demanda agregada e o grau de utilização efetivo e só posteriormente reduzir o crescimento da capacidade produtiva. Se a partir daí o investimento for reduzido novamente, o processo cumulativo se agrava e temos a conhecida "instabilidade fundamental" de Harrod (1939) (o mesmo processo funciona simetricamente no caso de um grau de utilização acima do normal).

Alguns autores, inclusive sraffianos (seguindo o caminho aberto por Kalecki, 1954), consideram que seria possível distinguir entre investimentos induzidos pela evolução da demanda e investimentos privados autônomos gerados por inovações tecnológicas. Este componente autônomo do investimento é visto como tendo o efeito de tornar obsoleta parte da capacidade produtiva já existente. 
Assim, de alguma forma estes investimentos seriam também gastos que não levariam a acréscimos líquidos da capacidade produtiva do setor privado da economia.

De qualquer maneira, em termos gerais a segunda condição geral necessária para que haja a possibilidade lógica do ajustamento da capacidade à demanda agregada seria a existência de gastos autônomos que não criam capacidade para o setor privado (mesmo que sejam investimentos autônomos em inovações como descrito acima). Chamaremos esta condição de condição 2. No restante desta seção veremos as dificuldades analíticas encontradas por autores sraffianos ligadas a essas duas condições.

\subsubsection{A abordagem de Eatwell e Milgate}

Eatwell (1979, reproduzido em Eatwell e Milgate, 1983) propõe que na posição normal da economia, onde os preços normais prevalecem, a capacidade produtiva esteja ajustada ao nível e à composição do produto e da demanda efetiva. E trata os níveis setoriais e agregado de investimento das empresas como exógenos. Mas se estamos num contexto onde a capacidade está ajustada à demanda, não faz sentido lógico tratar o investimento agregado como exógeno. Logo, já vemos aqui que Eatwell acaba por infringir a condição 1 da seção anterior. O mesmo tipo de tratamento se encontra no livro de Milgate (1982, cap. 6, especialmente seção B), baseado em tese de doutorado orientada por Eatwell, onde é proposta uma releitura da teoria da demanda efetiva de Keynes como sendo fundamentalmente uma teoria de longo prazo. Milgate (1982) chega a reconhecer que tal interpretação não é consistente com a suposição explícita de Keynes que toma o estoque de capital total como um dado, mas baseia sua interpretação na ideia de que Keynes achava, e com razão, que a determinação do produto pela demanda efetiva era uma proposição válida bem além de equilíbrios de curto prazo marshallianos, onde a composição do estoque de capital não está adequada à estrutura da demanda da economia ${ }^{16}$. O que nos interessa aqui é ressaltar que Milgate (1982) também não menciona a possível incoerência de falar de ajustamento da capacidade à demanda e supor o investimento agregado exógeno ao mesmo tempo, igualmente infringindo, portanto, a condição 1. Na introdução dos editores da coletânea Eatwell e Milgate (1983) mais uma vez este problema aparece.

Eatwell e Milgate (1983) estão corretos em afirmar que o equilibrio do produto em Keynes refletiria forças persistentes. E de fato, em Keynes não há grande mudança na passagem de um equilíbrio marshalliano de curto para um de longo prazo. Ocorre apenas uma gravitação dos preços dos seus níveis de equilíbrio de

(16) Note que Milgate (1982) se refere ao equilíbrio de longo prazo, tanto clássico quanto neoclássico, como incorporando a condição de que a composição do estoque de capital está ajustada à demanda. Já Ciccone (1986) fala composição do investimento bruto. 
curto prazo, iguais aos custos marginais, para seus níveis de longo prazo, iguais aos custos médios de longo prazo, conforme a composição do estoque de capital se ajusta à estrutura da demanda. No entanto, Garegnani chama a atenção para o fato de que a análise do processo de acumulação se dá num prazo bem mais longo que o longo prazo marshalliano (e dos economistas clássicos como depois esclarecido por Ciccone, 1986). Assim, para que haja ajustamento da capacidade à demanda, é preciso ir além da posição de longo prazo e discutir o processo de ajuste do estoque de capital à tendência da demanda ${ }^{17}$.

Não deixa de ser irônico constatar que a cobrança de algo sobre a endogeneidade do investimento seria desnecessária se Eatwell e Milgate não estivessem supondo posições de pleno ajustamento e caracterizassem a posição de longo prazo como faz Ciccone (1986). Somente em Eatwell (1983) aparece a discussão sobre a inconsistência do seu próprio tratamento anterior do investimento. O problema é colocado com bastante clareza:

The process is one of the adjustment of capacity to demand. Here the analysis encounters a difficulty. Demand has been supposed to be the independent variable, yet the process of adjustment of sectoral capacity to demand must involve changes in investment, one of the components of autonomous demand. At the aggregate level this difficulty is manifest in the instability of Harrod's warranted rate of growth. The 'two-sided' character of investment - that it creates capacity and determines demand - results in a cumulative process of expansion or decline, with no tendency for the mutual adjustment of capacity and demand, quite the contrary. The origin of the problem is that on the one hand investment is assumed to be the independent variable, whilst on the other hand variation in the composition and perhaps the overall size of investment is the mechanism by which capacity is adjusted to demand (Eatwell, 1983, p. 15).

E a seguir, propõe que a solução pode ser encontrada na própria análise de emprego de longo prazo de Keynes, referindo-se ao capítulo 5 da Teoria Geral, onde tal conceito é definido como o nível de emprego que corresponde a um dado estado de expectativas de longo prazo. Este nível de emprego supostamente corresponde a

(17) Garegnani em carta endereçada a Eatwell e Milgate e reproduzida como nota de rodapé no prefácio do livro Eatwell e Milgate (1983, prefácio, n. 2), diz: "the meaning of 'long run'cannot but be partly different when used in connection with a theory of aggregate output than when used for the theory of relative output. While the meaning of given plant or productive capacity remains, what is relevant for Marshall is the lack of congruence between relative capacity and demand in the several industries, What is relevant for a theory of aggregate output like that of Keynes is the lack of congruence between aggregate capacity and aggregate demand ... When this distinction is made it should be clear that Keynes is concerned with a short period analysis of aggregate output (the determination of the level of capacity utilization) and that a long period analysis of aggregate output, i.e., an analysis of the reciprocal adaptation of aggregate supply and aggregate demand is one and the same thing as a theory of accumulation. This is absent in Keynes apart from some hints". Eatwell e Milgate se limitam a apontar que não concordam inteiramente com esta passagem e que uma resposta iria requerer um novo livro. 
uma determinada capacidade de produção de longo prazo $^{18}$ e vai depender do montante de investimento efetuado a partir de tais expectativas, da função consumo e do efeito multiplicador. Seria este estado de expectativa a verdadeira variável independente a considerar e não o próprio investimento. $\mathrm{O}$ motivo pelo qual esse processo seria consistente pode ser melhor ilustrado pelo próprio autor:

The process may be overshoot ... but so long as the state of expectation may be supposed to be given then competition will tend to push the level of capacity toward that which is appropriate to sustain the long-term level of employment ... There is no reason to suppose that this will be a smooth process, but the usual oscillations and instabilities of multiplier-accelerator models will be damped by the fixed level of demand associated with the state of long-term expectation. (Eatwell, 1983, p. 283, grifo original).

$\mathrm{O}$ autor argumenta que o estado de expectativas está alicerçado numa complexa estrutura de instituições, financeiras e industriais, nacionais e internacionais, públicas e privadas. Portanto, a estabilidade do estado de expectativas seria proveniente da estabilidade do quadro institucional. Entende também que as principais condições institucionais que entram na formação de expectativas apresentariam mudanças relativamente lentas, de modo que as expectativas, mesmo sendo revistas com alguma base nas flutuações cíclicas de demanda, devem ser revistas de modo bem moderado, o que lhes confere estabilidade e confiabilidade. Os investidores, por exemplo, não reveriam seus níveis de investimentos em face a claros booms temporários de consumo.

O problema é: como, concretamente, seria possível se realizar essa intuição de Eatwell? Se os investimentos forem induzidos, as expectativas teriam de ser endógenas, baseadas na variação do nível de atividade, o que não se enquadra na proposta do autor, mas concilia a variação do estoque de capital com a taxa efetiva de crescimento da demanda; se autônomos, as expectativas seriam exógenas, determinadas por um "estado de confiança" de longo prazo, para onde se aproxima a sugestão do autor, mas deixando em aberto a questão: como seria racional para os empresários manter um determinado estado de confiança, criando, deliberadamente, capacidade ociosa não lucrativa, diante de um sistema concorrencial? Se o estado de expectativas é dado, as firmas não poderiam reagir neste caso. Mas se os investimentos reagem (algo aparentemente inevitável quando há concorrência), então as expectativas não podem ser consideradas dadas. Isto parece tornar a sugestão de Eatwell inconsistente estruturalmente com nossa condição $1^{19}$.

(18) Eatwell (1983) não dá base textual para sua suposição central de que estados de expectativas diferentes correspondem a estoques de capital fixo diferentes no capitulo 5 de Keynes (1936) e não parece haver referências a isto neste capítulo.

(19) A mesma crítica se aplica à formalização destas ideias apresentada por Park (2011). 


\subsubsection{A abordagem de Vianello}

Vianello (1985) se propôs explicitamente a discutir o processo de ajuste da capacidade à demanda. Embora posteriormente Vianello (1989) tenha adotado a visão de longo prazo de Ciccone (1986), não requerendo que tal ajustamento seja completo, ele utiliza basicamente o esquema de análise do artigo de $1985 \mathrm{em}$ diversas contribuições posteriores. Tais contribuições têm como objetivo central criticar as análises da relação entre distribuição de renda, taxa de lucro e acumulação de capital respectivamente de Kalecki (Vianello, 1989), Joan Robinson (Vianello, 1996) e dos neokaleckianos (Vianello; Ciampalini, 2000). O que nos interessa aqui é apenas a forma especifica como é tratado o investimento em todos estes trabalhos. Em seu esquema analítico simplificado, a taxa de crescimento agregado do nível de investimentos em geral é exógena. Boa parte da discussão consiste apenas em mostrar corretamente que não há motivo algum para que o investimento cresça continuamente à taxa garantida de Harrod (que implicaria que em todos os períodos o investimento se ajustaria inteiramente à poupança de plena capacidade). E apontar que isto significa que a taxa de acumulação correspondente a esta taxa garantida não nos dá nenhuma informação relevante sobre o ritmo em que a economia está de fato acumulando capital em média ao longo do tempo (seguindo de perto as ideias de Garegnani, 1992, 2015).

Ao mesmo tempo, Vianello afirma que existe uma tendência de ajustamento da capacidade à demanda e diz que os desvios deste ajustamento são de natureza temporária. E completa dizendo que:

... a difference must be recognized, in long run analysis between two kinds of investment decisions, those intended to restore or preserve the normal degree of utilization, and those intended for other purposes, such as the introduction of new products or new processes. It is the latter decisions that determine the pace of accumulation (Vianello, 1985, p. 86).

Adicionalmente, em Vianello (1989b) e Vianello e Ciampalini (2000), acrescenta que o investimento pode ser afetado diretamente pela taxa normal de lucro. Por exemplo, pode se reduzir como reação direta a uma queda da taxa normal de lucro advinda de um aumento do salário real.

Nenhuma dessas ideias sobre como se determinam os investimentos a longo prazo são integradas com o esquema analítico formal utilizado por Vianello nestes artigos. E não fica nada claro como os investimentos induzidos cujo objetivo seria restabelecer a utilização normal da capacidade podem ser independentes do montante de investimentos efetuados "por outros motivos". Com base neste tipo de insight verifica-se que, não havendo a injeção de poder de compra adicional, que não cria mais capacidade produtiva, não há como equacionar coerentemente a sugestão 
de Vianello, pois, essencialmente, está-se infringindo a condição 2 da seção acima e, portanto, não é possível que a capacidade se ajuste à demanda no longo prazo.

No caso do investimento advindo do estímulo de uma maior taxa normal de lucro, é bastante implausível que, motivadas apenas por isso, as empresas criem capacidade produtiva para a qual não há perspectiva de demanda, isto é, capacidade ociosa não desejada e nada lucrativa. Já no caso em que investidores reduzem seus investimentos, desestimulados pela queda da taxa normal de lucro, fica o questionamento sobre se o menor crescimento da capacidade produtiva resultante disso, combinado com o crescimento do consumo agregado advindo da maior parcela salarial e do multiplicador, não aumentaria o grau efetivo de utilização da capacidade existente e estimularia novamente os investimentos induzidos de outras empresas $^{20}$. A rigor, em nenhum destes trabalhos (Vianello 1985, 1989b, 1996; Vianello; Ciampalini, 2000), o autor nos dá alguma indicação de como se efetuaria o ajustamento da capacidade à demanda, levando em conta os efeitos-capacidade destes vários determinantes possíveis do investimento.

Além desta ambiguidade sobre o caráter autônomo/exógeno ou induzido/endógeno do investimento total, Vianello usa, em todos estes trabalhos, um esquema analítico onde todo o consumo é induzido e, portanto, para uma dada distribuição de renda, proporcional ao produto. Assim, o investimento e o consumo sempre variam na mesma proporção: "empresários não escolhem a proporção da renda a qual é devotada ao investimento" (Vianello, 1985, p. 19, tradução nossa). Neste caso, no entanto, como vimos acima, o ajustamento da capacidade à demanda é logicamente impossível e acaba infringindo, em diferentes momentos, as condições 1 e 2 .

Se restringirmos os "outros motivos" apenas aos efeitos de investimentos autônomos em inovações poderia então talvez haver uma saída para estas inconsistências. No entanto, a hipótese de que investimentos autônomos em inovações não criam capacidade produtiva adicional para a economia como um todo e, portanto, podem cumprir papel semelhante à expansão da "demanda final" autônoma, embora comum na literatura, é em si bastante problemática porque ignora o efeito negativo sobre o investimento dos não inovadores que perdem parcela de mercado. Investimentos em "novos produtos" podem simplesmente reduzir a demanda por produtos antigos se não houver uma adicional injeção autônoma de poder de compra monetário para permitir o aumento do consumo agregado (ou então deve-se postular uma redução na propensão marginal a poupar da economia). Por outro lado, inovações que criam "novos processos" permitem às firmas inovadoras roubarem parcelas de mercado das firmas que ainda operam processos antigos, mas

(20) Para críticas de autores sraffianos a ideia de que o investimento pode ser função direta do nível da taxa de lucro normal, ver Cesaratto (2015). 
também não aumentam a demanda final agregada. Portanto, os investimentos autônomos em inovação, mesmo quando, após um tempo, não resultem em acréscimo líquido de capacidade, na medida em que provoquem uma redução compensatória dos investimentos induzidos (que tentam restabelecer o grau de utilização normal ao se depararem com capacidade ociosa não planejada devido à perda de parcelas de mercado), acabam, neste caso, também não resultando em acréscimo líquido de demanda em relação à capacidade total final. Isto evidencia que embora o investimento autônomo se manifeste como demanda autônoma, esta demanda não atende a condição número 2 , ou por ser criadora de capacidade adicional, ou por tornar obsoleta a capacidade de outros competidores, tende a reduzir compensatoriamente o investimento de outros investidores, o que cancela o efeito da demanda autônoma do investidor inovador ${ }^{21}$.

\section{Resgatando os elementos originais de 1962: a solução de Garegnani (2015)}

Com base no que vimos até aqui, podemos afirmar que nenhum dos textos analisados até agora atende simultaneamente às duas condições lógicas necessárias para o ajustamento da capacidade a demanda (apresentadas no item 4.3.1).

No entanto, a base para o tratamento analítico satisfatório desta questão já se encontra no relatório de 1962 de Garegnani, no capítulo 4 da parte teórica que acabou só sendo publicado (postumamente) em 2015. Neste texto Garegnani argumenta que os determinantes do investimento a longo prazo podem ser reduzidos a apenas dois: a evolução (esperada e posteriormente efetiva) do que chama de "demanda final" e o progresso técnico. Comecemos com a demanda final, segundo o autor "mais adequadamente definida como a demanda cujo propósito não seja a produção adicional de bens dentro da economia. Logo, engloba demanda interna por bens de consumo e demanda por exportações líquidas" (Garegnani, 2015, p. 12, tradução nossa).

No que tange à demanda por investimento, Garegnani primeiramente argumenta que "o investimento visando prover equipamento produtivo para aquele investimento diretamente induzido pela expansão da demanda final é, de fato, tratado como investimento induzido pela demanda final" (Ibidem, p. 12, tradução nossa). Trata-se, de fato, do reconhecimento do "princípio acelerador", que permite que a demanda tome a frente da causalidade na relação entre investimento e poupança:

The principle that the level of investment depends on the growth of final demand is variously employed in cycle theory and in the theory of economic growth, in the form of the 'acceleration principle'.... Any increase in the

(21) Para estas (e outras) críticas à noção de crescimento liderado por investimentos autônomos em inovações ver Cesaratto et al. (2003) e Caminati (1987). 
demand for a good will, after an initial period in which production pushes up against the capacity limits of the firms in an industry, eventually induce... an increase in investment. What has for a long time hindered economic theory from taking account of this key factor determining the growth of the economic system has been the principle of the tendency for investment and the saving obtainable from full capacity utilization to equalize. According to that principle, investment and the growth of the productive system appeared to be completely independent of the markets for goods. The growth of markets came about only as a consequence of the growth of the productive system, without any possibility of a reversal of the relation between cause and effect. As soon as the principle of the equalization of investment and capacity saving is abandoned, demand inevitably takes on a causal role in the expansion of the productive system (Ibidem, p. 12).

Por outro lado, embora o autor reconheça que parte do consumo é induzido pelo próprio aumento da produção, deixa claro que são os elementos autônomos da "demanda final" que têm um papel central na sustentação do investimento a longo prazo.

Recognizing that the growth of demand has an autonomous role in determining the growth of output does not however preclude the possibility of a relationship also running in the opposite direction: the growth of output with the consequent increase in realized incomes will lead to an increase in aggregate demand. But in a system in which investment decisions are decentralized, the expansion of demand due to an increase in the output of a single entrepreneur will have only a negligible effect on the demand for that firm's output,... In such an economy, entrepreneurs will have no reason ... to expand the production of any good, and hence aggregate output, unless the demand for that good is already increasing or is expected to increase (Ibidem, p. 13).

Argumenta também (Ibidem, p. 13 n. 22) que o investimento não depende da taxa de lucros realizada nos novos investimentos pois, como o mesmo é induzido pela demanda, é a taxa de lucro realizada que tende a se ajustar à taxa normal (dada) de $\operatorname{lucros}^{22}$ uma vez que o estoque de capital é que se ajusta à demanda, fazendo o grau de utilização efetivo se aproximar do normal. Nesta mesma linha, aponta que lucros retidos também não são determinantes do investimento. Pelo contrário, no agregado, os lucros retidos são determinados pela massa de lucro realizada, resultante dos investimentos, uma vez que o aumento do investimento agregado aumenta o grau efetivo de utilização da capacidade que, por sua vez, aumenta a taxa de lucro realizada (mas não a normal).

Passemos agora ao progresso técnico. Aqui, Garegnani completa seu argumento dizendo que "um aumento do investimento independente do aumento da

(22) Como a taxa normal de lucros se move no longo prazo na mesma direção que a taxa de juros, Garegnani (1978-1979) considera que o nível da taxa de juros também não tem efeito relevante sobre o investimento das empresas, somente afetando o investimento residencial. 
demanda final ocorre no caso em que o investimento é induzido por inovações" (Ibidem, 2015, p. 12, tradução nossa). Em geral, no caso de inovações de processo:

...the effect of innovations must generally be to increase the level of aggregate investment through an accelerated obsolescence of existing plants. This obsolescence may also take the form of the establishment of new branches of industry (the industries for new products) accompanied by the disappearance of other branches of industry (Ibidem, p. 14).

Este efeito, isoladamente, mesmo aceitando que aumente inicialmente o nível agregado de investimento, não parece ser capaz de gerar uma tendência de crescimento de longo prazo do investimento (conforme visto no item 4.3.3). No caso de inovações de produto, Garegnani afirma que existe a possibilidade de que um mercado possa se desenvolver sem, simultaneamente, diminuir o mercado de outros bens, mas não apresenta uma análise detalhada dos elementos que transformariam esta possibilidade em realidade. De qualquer forma, argumenta em seguida que "é, acima de tudo, do primeiro tipo de investimento - investimento induzido por uma expansão da demanda final - que podemos esperar o resultado de um crescimento do estoque de capital" (Ibidem, p. 15, tradução nossa). De fato, em um outro trabalho Garegnani afirma que:

I believe that a satisfactory long-period theory of output does not require much more than (a) an analysis of how investment determines saving through changes in the level of productive capacity (and not only through changes in the level of utilization of productive capacity); (b) a study of the factors affecting the long-run levels of investment; and (c) a study of the relation between consumption expenditure and aggregate income. Theoretical and applied studies have already prepared much material in the last two fields (Garegnani, 1983, p. 75).

Nesta lista de Garegnani (1983), as hipóteses de Garegnani (2015) de que o investimento é basicamente induzido pela demanda se referem ao item (b) e a de que existem componentes autônomos na demanda final se refere ao item (c). E as duas hipóteses conjuntamente provêm as condições lógicas 1 e 2, necessárias, como vimos acima, para que a capacidade possa se ajustar à tendência da demanda, o que, essencialmente, resolve o cerne de toda a dificuldade analítica entre os autores aqui trabalhados 23 .

(23) Tal questão só tem ficado mais clara nos debates que começaram a partir de meados dos anos 1990 e não são discutidos aqui, sobre o modelo do supermultiplicador sraffiano (ou clássico-keynesiano). Sobre esse debate específico ver Moreira e Serrano (2017). Sobre o supermultiplicador de gastos autônomos improdutivos com distribuição exógena ver as diferentes versões de Bortis (1979, 1997), e Serrano (1995a, 1995b) e De Juan (2005). Para contribuições recentes a este debate ver os artigos do simpósio organizado por Cesaratto e Mongiovi (2015) na Review of Political Economy onde se encontra Garegnani (2015). 


\section{Referências bibliográficas}

BORTIS, H. Foreign resources and economic development from the early fifties to the oil crisis: a consideration of some theoretical and empirical aspects. Fribourg, Suiça: Editions Universitaires Fribourg, 1979.

BORTIS, H. Institutions, behaviour and economic theory - A contribution to classical-Keynesian political economy. Cambridge: Cambridge University Press, 1997.

CAMINATI, M. Technical innovations, life of equipment and effective demand. Political Economy, v. 3, n. 2, 1987.

CESARATTO, S. Neo-Kaleckian and Sraffian controversies on the theory of accumulation. Review of Political Economy, v. 27, p. 154-182, 2015.

CESARATTO, S.; SERRANO, F.; STIRATI, A. Technical change, effective demand and employment. Review of Political Economy, v. 15, p. 33-52, 2003.

CESARATTO, S.; MONGIOVI, G. Pierangelo Garegnani, the classical surplus approach and demand-led growth: introduction to the symposium. Review of Political Economy, v. 27, n. 2, p 103-110, Apr., 2015.

CICCONE, R. Accumulation and capacity utilization: some critical considerations on Joan Robinson's theory of distribution. Political economy: studies in the surplus approach, v. 2, p. 17-36, 1986. (reprinted in: Bharadwaj; Schefold, 1990).

CICCONE, R. Accumulation, capacity utilization and distribution: a reply. Political Economy, v. 3, n. 1. 1987.

CICCONE, R. Capacity utilization, mobility of capital and the classical process of gravitation. In: CICCONE, R.; GEHRKE, C.; MONGIOVI, G. Sraffa and modern economics, v. 2. London: Routledge, 2011.

DE-JUAN, O. Paths of accumulation and growth: towards a keynesian long-period theory of output. Review of Political Economy, v. 17, n. 2, p. 231-252, 2005.

EATWELL, J. Theories of value, output and employment. Reprinted. In: EATWELL, J.; MILGATE, M. (Ed.). Keynes's economics and the theory of value and distribution. Duckworth, London, (1979 [1983]).

EATWELL, J. The long-period theory of employment. Cambridge Journal of Economics, v. 7, p. 269-285, 1983.

EATWELL, J. The theory of value and the foundations of economic policy. In: Memoriam Pierangelo Garegnani. Contributions to Political Economy, v. 31, n. 1, p. 1-18, 2012. 
EATWELL, J.; MILGATE, M. (Ed.). Keynes's economics and the theory of value and distribution. Duckworth, London, 1983.

GAREGNANI, P. Il capitale nelle teorie della distribuzione. Milan: Giuffré, 1960.

GAREGNANI, P. Il problema della domanda effetiva nello sviluppo economico italiano. Roma: SVIMEZ, 1962.

GAREGNANI, P. Notes on consumption, investment and effective demand. Cambridge Journal of Economics, v. 2-3, p. 63-82, 335-353, 1978-1979. (Reprinted in: Eatwell; Milgate, 1983).

GAREGNANI, P. Reply to Joan Robinson. Reprinted in: EATWELL, J.; MILGATE, M. (Ed.). (1979a [1983]).

GAREGNANI, P. Valore e domanda effettiva. Torino: Einaudi, 1979b.

GAREGNANI, P. Summary of the paper "some notes for an analysis of accumulation", paper presented at the conference. Theories of Accumulation and the Control of the Economy, 1982.

GAREGNANI, P. Two routes to effective demand: a comment on Kregel. In: KREGEL, J. (Ed.). Distribution, effective demand and international economic relations. London: Macmillan, 1983.

GAREGNANI, P. Some notes on capital, expectations and the analysis of changes. In: FEIWEL, G. R. (Ed.). Joan Robinson and modern economic theory. London and Basingstoke: Macmillan, 1989.

GAREGNANI, P. Some notes for an analysis of accumulation. In: HALEVI, J.; LAIBMAN, D.; NELL, E. J. (Ed.). Beyond the steady state: a revival of growth theory. New York: St Martin's Press, 1992.

GAREGNANI, P.; PALUMBO, A. Accumulation of capital. In: KURZ, H-D.; SALVADORI, N. (Ed.). The Elgar companion to classical economics (A-K). Cheltenham: Edward Elgar, 1998.

GAREGNANI, P. Professor Foley and classical policy analysis. Review of Political Economy, v. 19, n. 2, p. 221-242, 2007.

GAREGNANI, P. On the present state of the capital controversy. Cambridge Journal of Economics, v. 36, n. 6, p 1417-1432, 2012.

GAREGNANI, P. The problem of effective demand in Italian economic development: on the factors that determine the volume of investment. Review of Political Economy, v. 27, n. 2, p. 111-133, 2015.

HARROD, R. F. An essay in dynamic theory. Economic Journal, v. 49, n. 193, p. 14-33, 1939. 
KEYNES, J. M. The general theory of employment, interest and money. London: Macmillan, 1936.

KURZ, H. Normal position and capacity utilization. Political Economy, v. 2, n. 1, p. 37-54, 1986.

MILGATE. Capital and employment. London: Macmillan, 1982.

MOREIRA, V. G. Demanda efetiva e crescimento na abordagem Sraffiana: fundamentos teóricos e aplicações. Dissertação (Mestrado)-IE-UFRJ, 2007.

MOREIRA, V. G.; SERRANO, F. $O$ debate envolvendo o efeito acelerador e a controvérsia sobre o modelo do supermultiplicador sraffiano. Rio de Janeiro: IEUFRJ, 2017. Mimeografado.

PARK, M. S. Alternative routes of adjustment of saving to investment in the long period. In: GEHRKE, C.; SALVADORI, N. (Ed.). Keynes, Sraffa, and the criticism of neoclassical theory essays in honour of Heinz D. Kurz. Routledge, 2011.

PETRI, F. Pierangelo Garegnani. In: ARESTIS, P.; SAWYER, M. (Ed.). A biographical dictionary of dissenting economists. $2^{\text {th }}$ ed. Cheltenham, U.K.: Edward Elgar, 2000.

ROBINSON, J. Essays in the theory of economic growth. London: Macmillan. 1962. ROBINSON, J. The accumulation of capital. London: Macmillan. 1956.

ROBINSON, J. Garegnani on effective demand. Cambridge Journal of Economics, v. 3, p. 179-181, 1979.

SERRANO, F. Long period effective demand and the Sraffian supermultiplier. Contributions to Political Economy, v. 14, p. 67-90, 1995a.

SERRANO, F. The Sraffian supermultiplier. Unpublished Ph.d. Dissertation. Cambridge University, 1995 b.

SRAFFA, P. Production of commodities by means of commodities: prelude to a critique of economic theory. Cambridge: Cambridge University Press, 1960.

STEINDL, J. Maturity and stagnation in American capitalism. Oxford: Basil Blackwell, 1952.

VIANELLO, F. The pace of accumulation. Political Economy: studies in the surplus approach, v. 1, n. 1, p. 69-87, 1985.

VIANELLO, F. Effective demand and the rate of profit: some thoughts on Marx, Kalecki and Sraffa. In: SEBASTIANI, M. (Ed.). Kalecki's relevance today. New York: St. Martin's Press, 1989. p. 164-190. 
VIANELLO, F. Joan Robinson on normal prices (and the normal rate of profits). In: MARCUZZO, M. C.; PASINETTI, L. L.; RONCAGLIA, A. (a cura di). The economics of Joan Robinson. New York: Routledge, 1996.

VIANELLO, F.; CIAMPALINI, A. Concorrenza, accumulazione del capitale e saggio del profitto. Critica al moderno sottoconsumismo. In: PIVETTI, M. (a cura di). Piero Sraffa. Contributi per una biografia intellettuale. Roma: Carocci, 2000. 